\title{
Author Correction: Epigenetic scarring of exhausted T cells hinders memory differentiation upon eliminating chronic antigenic stimulation
}

Mohamed S. Abdel-Hakeem, Sasikanth Manne, Jean-Christophe Beltra, Erietta Stelekati, Zeyu Chen, Kito Nzingha, Mohammed-Alkhatim Ali, John L. Johnson, Josephine R. Giles, Divij Mathew, Allison R. Greenplate, Golnaz Vahedi and E. John Wherry

Correction to: Nature Immunology 10.1038/s41590-021-00975-5, published online 26 July 2021

In the originally published version of this Article, there were errors in Fig. 6b, main text and Extended Data Fig. 8a caption.

Specifically, in Fig. 6b, the labels at top of the heatmap, now reading left-to-right as "REC- $\mathrm{T}_{\mathrm{EX}}$ " and " $\mathrm{T}_{\mathrm{EX}}$," were in reverse order. In the Results section, under heading "Epigenetic scars in REC- $\mathrm{T}_{\mathrm{EX}}$ limit core memory circuits," second paragraph, fourth sentence, the text now reading "Of the 140 OCRs that were more accessible in REC- $\mathrm{T}_{\mathrm{EX}}$ compared to $\mathrm{T}_{\mathrm{MEM}}$ and $\mathrm{T}_{\mathrm{EX}}$ (Fig. 5c), only a handful (for example, $Z f p 3612$ ) showed increased expression of the associated gene in REC- $\mathrm{T}_{\mathrm{EX}}$ compared to $\mathrm{T}_{\mathrm{EX}}$ (Extended Data Fig. 8a)" overwrote the previous sentence (Of the 140 OCRs that were more accessible in REC- $T_{E X}$ compared to $T_{M E M}$ (Fig. 5c), only a handful (for example, Zfp362) showed increased expression of the associated gene (Extended Data Fig. 8a)). In Extended Data Fig. 8a caption, the sentence now reading "Genes from scRNAseq with significantly different expression between REC- $\mathrm{T}_{\mathrm{EX}}$ and $\mathrm{T}_{\mathrm{EX}}$ that are associated with more accessible OCRs in REC- $\mathrm{T}_{\mathrm{EX}}$ compared to both $\mathrm{T}_{\mathrm{EX}}$ and $\mathrm{T}_{\mathrm{MEM}}$ " overwrote the previous caption (a, Genes from scRNAseq with significantly different expression between REC- $\mathrm{T}_{\mathrm{EX}}$ and $\mathrm{T}_{\mathrm{MEM}}$ that also had associated significant differences in the chromatin accessibility).

The changes have been made to the online version of the Article.

Published online: 29 September 2021

https://doi.org/10.1038/s41590-021-01057-2

(c) The Author(s), under exclusive licence to Springer Nature America, Inc. 2021 